\title{
Color name as a function of wavelength and instruction'
}

\author{
ALEezA CERF BEARE, WESTINGHOUSE DEFENSE AND SPACE CENTER, AEROSPACE DIVISION, BALTIMORE, MD.
}

MICHAEL H. SIEGEL, RIPON COLLEGE, RIPON, WISCONSIN

A series of experiments were performed to determine the effects of instructions upon color naming data. Although color name is basically a function of stimulus wavelength, even slight changes in the response categories available for the $S$ led to substantial changes in the pattern of $S s^{\prime}$ response allocation.

Recently, several researchers have shown interest in color naming as a technique. Boynton, Schafer, and Neun (1964) demonstrated that such a technique can be applied to the study of central fixation. Later reports employed color naming to study the BezoldBriucke effect (Boynton \& Gordon, 1965) and the influence of exposure duration and luminance on naming (Luria, 1967).

It has for some time been clear that there is a relation between stimulus wavelength and color name (Beare, 1963). It is not clear how this relation is influenced by the instructions which are furnished to Ss. All of the recent studies employing color naming as an experimental technique have assumed that the particular set of instructions which they employed was satisfactory. If, however, instructions exert a significant influence on the data obtained, comparing sets of data obtained in response to differing instructions becomes a questionable practice.

It is here assumed that naming instructions do indeed have an effect upon data, and that this effect depends on at least two components. The first component is the number of names allowed Ss, and the second, the nature of the name they are permitted. The present study, then, attempts to assess the role played by instructions given to Ss when the task is to name colors. It is hoped that the results will serve as a guideline for the future employment of the color naming technique.

\section{Apparatus}

A Bausch and Lomb $500 \mathrm{~mm}$ monochromator provided the stimulus. A sector shutter permitted discrete $0.2 \mathrm{sec}$ stimulus exposures. The stimulus was circular and subtended $3 \mathrm{deg}$ at the observer's eye. Wavelength settings from 400 through $600 \mathrm{~m} \mu$ were employed. The stimulus could be set to either of two different luminance levels, .1 or $1.0 \mathrm{ft}-\mathrm{L}$, while the area surrounding the stimulus was white and was maintained at a luminance of .1 ft-L. Calibrations were made both before and after the experiment upon the wavelength setting of the monochromator, the luminance levels of the stimulus and surround, and the duration of the exposure. No changes from the pre-experimental values were detected.

\section{Subjects}

Subjects were 24 young men from the volunteer pool available to the Edgewood Arsenal laboratories. All reported English as their native tongue, had normal color vision, and were emmetropic or wore corrective lenses during the experiment. Before the first experimental session, each $S$ received a training session. Observation was made with the right eye only.

\section{Procedure}

The spectrum was sampled in $10 \mathrm{~m} \mu$ intervals from $400 \mathrm{~m} \mu$ through $640 \mathrm{~m} \mu$. Between 560 and 590 $\mathrm{m} \mu$ only $5 \mathrm{~m} \mu$ steps were used so that the yellow region would be thoroughly sampled. Twenty-eight wavelengths were presented in random order. An experimental session consisted of three runs through the spectrum. Each $S$ served for 10 sessions, five at each of the two luminance levels.

Before each experimental session, Ss were told what color names would be available. Ss were then required to respond with an acceptable color name following a ready signal. Dividing the group of Ss into six subgroups allowed for a different subgroup to serve in each of the six experimental conditions defined below.

\section{Experimental Conditions}

(A) Free choice: No color names were prescribed. Ss were asked to name each color they saw as accurately as they could.

(B) 1. Four color names: Red, Yellow, Green, or Blue were permitted.

2. Four color names: Red, Orange, Green, or Blue were to be used.

(C) Four names with compounds: Ss were allowed the use of the four color names of Condition B-1 as well as the following combinations: Red-Blue, Blue-Green, Yellow-Green, and Yellow-Red. Instructions regarding name precedence in compound naming were purposely omitted.

(D) Six names: Only the color names Purple, Blue, Green, Yellow, Orange, and Red were permitted.

(E) Six names with compounds: In addition to the six color names of Condition D, Ss could use the following compounds: Blue-Purple, Blue-Green, Yellow-Green, Yellow-Orange, and Orange-Red. As 
Table 1. Number of Times Each Name was Used for All Conditions

\begin{tabular}{|c|c|c|c|c|c|c|c|c|c|c|c|c|}
\hline \multirow{2}{*}{$\begin{array}{l}\text { Luminance Level: } \\
\text { Exp. Condition: } \\
\text { Name }\end{array}$} & \multirow[b]{2}{*}{ A } & \multicolumn{3}{|c|}{$0.1 \mathrm{Ft}-\mathrm{L}$} & \multirow[b]{2}{*}{ D } & \multirow[b]{2}{*}{$E$} & \multirow[b]{2}{*}{ A } & \multicolumn{3}{|c|}{$1.0 \mathrm{Ft}-\mathrm{L}$} & \multirow[b]{2}{*}{ D } & \multirow[b]{2}{*}{$E$} \\
\hline & & B.1 & B-2 & C & & & & B-1 & B-2 & $\mathrm{C}$ & & \\
\hline $\begin{array}{l}\text { Purple } \\
\text { Purple-Blue }\end{array}$ & 218 & & & & 236 & $\begin{array}{r}209 \\
8\end{array}$ & 113 & & & & 148 & $\begin{array}{r}171 \\
10\end{array}$ \\
\hline Blue-Red & & & & 194 & & & & & & 126 & & \\
\hline $\begin{array}{l}\text { Blue } \\
\text { Blue-Green }\end{array}$ & $\begin{array}{r}305 \\
3\end{array}$ & 537 & 526 & $\begin{array}{l}308 \\
224\end{array}$ & 309 & $\begin{array}{r}325 \\
57\end{array}$ & $\begin{array}{r}371 \\
3\end{array}$ & 509 & 538 & $\begin{array}{l}346 \\
163\end{array}$ & 349 & $\begin{array}{r}384 \\
59\end{array}$ \\
\hline Green & 654 & 613 & 695 & 392 & 550 & 503 & 574 & 560 & 657 & 337 & 490 & 401 \\
\hline Yellow-Green & 8 & & & 137 & & 93 & 14 & & & 167 & & 136 \\
\hline $\begin{array}{l}\text { Yellow } \\
\text { Yellow-Red }\end{array}$ & 4 & 204 & & $\begin{array}{r}42 \\
221\end{array}$ & 178 & 95 & 98 & 238 & & $\begin{array}{r}91 \\
191\end{array}$ & 225 & 105 \\
\hline Yellow-Orange & 2 & & & & & 24 & 4 & & & & & 64 \\
\hline Orange & 234 & & 217 & & 185 & 165 & 224 & & 286 & & 168 & 157 \\
\hline Orange-Red & 1 & & & & & 45 & 5 & & & & & 52 \\
\hline $\begin{array}{l}\text { Red } \\
\text { Gold }\end{array}$ & $\begin{array}{r}192 \\
14\end{array}$ & 326 & 242 & 162 & 222 & 156 & 199 & 313 & 199 & 199 & 240 & 141 \\
\hline
\end{tabular}

in Condition $C$, no instructions about name precedence in compound naming were given.

\section{Results}

Table 1 presents the total number of times each name occurred in each experimental condition for both luminance levels. Table 2 presents the median wavelength for each name distribution. Table 3 provides statistical comparisons between some of the medians from Table 2, for the high luminance condition. The statistical evaluation follows the Median Test (Siegel, 1956).

Figure 1 shows the results for Condition $A$ for both luminances, in which choice of name was unrestricted. Although a great many different color names were employed at both luminance levels, only five distinct modes appear: Purple, Blue, Green, Orange, and Red. All peak at $100 \%$ except Orange at the low luminance. Curves for Yellow never approached $100 \%$ and are shown to be the most profoundly influenced by differences in luminance. Peak frequency for Yellow dropped from over $60 \%$ at high luminance to approximately $30 \%$ at low luminance. There was no shift in wavelength for the named colors as a function of the two different luminance levels.

The free response condition yielded a total of eight categories, represented by separate curves at the low luminance and seven at the high luminance. These represent names which occurred either with a frequency greater than four or over a minimum wavelength range of three adjacent wavelength points. Names which occurred with a frequency below either of these criteria included Turquoise, Aquamarine, Chartreuse, Beige, and Lemon.

Figures 2 and 3 show Conditions B-1 and B-2, respectively. Condition $\mathrm{B}-1$ divided the spectrum into Blue, Green, Yellow, and Red. Yellow was replaced by Orange in Condition B-2. Figures 2 and 3 show all distributions peaking at $100 \%$ except Yellow in B-1. As in Condition A, the peak percent for Yellow was greater at the brighter of the two luminance levels; however, there was no shift in the wavelength location of any of the four curves either in Condition B-1 or B-2 as a function of the change in luminance

Table 2. Median of Each Name Distribution for All Conditions $(\mathrm{m} \mu)$

\begin{tabular}{|c|c|c|c|c|c|c|c|c|c|c|c|c|}
\hline \multirow{2}{*}{$\begin{array}{l}\text { Luminance Level: } \\
\text { Exp. Condition: } \\
\text { Name }\end{array}$} & \multicolumn{6}{|c|}{$0.1 \mathrm{Ft}-\mathrm{L}$} & \multicolumn{6}{|c|}{$1.0 \mathrm{Ft}-\mathrm{L}$} \\
\hline & A & B-1 & B-2 & C & D & $E$ & A & B. 1 & B-2 & C & D & $E$ \\
\hline $\begin{array}{l}\text { Purple } \\
\text { Purple-Blue }\end{array}$ & 418.5 & & & & 419.8 & $\begin{array}{l}417.5 \\
442.5\end{array}$ & 410 & & & & 423 & $\begin{array}{l}415.5 \\
436.6\end{array}$ \\
\hline Blue-Red & & & & 419.4 & & & & & & 421.4 & & \\
\hline $\begin{array}{l}\text { Blue } \\
\text { Blue-Green }\end{array}$ & $\begin{array}{l}463.9 \\
490\end{array}$ & 444.9 & 446.8 & $\begin{array}{l}458.2 \\
507.5\end{array}$ & 465 & $\begin{array}{l}463.1 \\
494.7\end{array}$ & $\begin{array}{l}449.8 \\
490\end{array}$ & 442.5 & 446.5 & $\begin{array}{l}459.8 \\
508.7\end{array}$ & 463.5 & $\begin{array}{l}462.2 \\
497.8\end{array}$ \\
\hline $\begin{array}{l}\text { Green } \\
\text { Yellow-Green }\end{array}$ & $\begin{array}{l}552.7 \\
576\end{array}$ & 540.7 & 548.7 & $\begin{array}{l}554.1 \\
575.7\end{array}$ & 528.3 & $\begin{array}{l}541.7 \\
571.1\end{array}$ & $\begin{array}{l}529.6 \\
562.5\end{array}$ & 541.5 & 546.2 & $\begin{array}{l}540.9 \\
573\end{array}$ & 536.7 & $\begin{array}{l}538.1 \\
568.1\end{array}$ \\
\hline $\begin{array}{l}\text { Yellow } \\
\text { Yellow-Red }\end{array}$ & 582.8 & 584.3 & & $\begin{array}{l}588.8 \\
602.5\end{array}$ & 578.6 & 583.8 & 573.6 & 583.9 & & $\begin{array}{l}582.9 \\
599.9\end{array}$ & 576.7 & 584.2 \\
\hline Yellow-Orange & 585 & & & & & 593.7 & 577.5 & & & & & 583.3 \\
\hline Orange & 598.2 & & 595.1 & & 597.4 & 603 & 587.7 & & 594.7 & & 595.1 & $\begin{array}{l}604.6 \\
623.7\end{array}$ \\
\hline Orange-Red & 610 & & & & & 617.7 & 610 & & & & & 623.7 \\
\hline $\begin{array}{l}\text { Red } \\
\text { Gold }\end{array}$ & $\begin{array}{l}631.5 \\
578.8\end{array}$ & 612.8 & 629.2 & 635.7 & 631.5 & 635.3 & 623.4 & 624 & 633.4 & 633.5 & 620 & 636.9 \\
\hline
\end{tabular}


Table 3. Comparisons of Differences in Name-DistributionsMedians Across Two Conditions. High Luminance Level Only

\begin{tabular}{|c|c|c|c|}
\hline Name & $\begin{array}{l}\text { Compared } \\
\text { Conditions* }\end{array}$ & $x^{2}$ & $\begin{array}{l}\text { Significant at } \\
\text { Confid. Level }\end{array}$ \\
\hline \multirow{2}{*}{$\begin{array}{l}\text { Red } \\
\text { Red }\end{array}$} & B- $2 \times$ B- 1 & 40.805 & .005 \\
\hline & $E \times C$ & 5.008 & .025 \\
\hline Red & $D \times A$ & 17.1859 & .005 \\
\hline \multirow{3}{*}{$\begin{array}{l}\text { Red } \\
\text { Green } \\
\text { Green }\end{array}$} & \multirow{2}{*}{$\begin{array}{l}C \times D \\
B-2 \times B-1\end{array}$} & \multirow{3}{*}{$\begin{array}{c}206.156 \\
2.84 \\
0.797\end{array}$} & \multirow{2}{*}{$\begin{array}{l}.005 \\
.05\end{array}$} \\
\hline & & & \\
\hline & $C \times E$ & & - \\
\hline Green & $C \times D$ & 7.9369 & .005 \\
\hline Green & $D \times A$ & 1.8074 & -- \\
\hline Blue & $E \times C$ & 1.725 & -- \\
\hline Blue & $D \times C$ & 3.206 & .05 \\
\hline Blue & $A \times D$ & 43.818 & .005 \\
\hline Blue-Green & $C \times E$ & 7.310 & .005 \\
\hline Yellow-Green & $C \times E$ & 11.595 & .005 \\
\hline Yellow & $E \times C$ & 9.969 & .005 \\
\hline Yellow & $C \times D$ & 14.4659 & .005 \\
\hline Yellow & $D \times A$ & 19.7174 & .005 \\
\hline Orange & $D \times A$ & 135.2166 & .005 \\
\hline Yellow-Red in & Orange in $D$ & 2.976 & .05 \\
\hline Purple & $D \times A$ & 117.860 & .005 \\
\hline
\end{tabular}

- That condition having the median with the longer wavelength is the first listed in each pair of compared conditions.

level. The wavelength range for Orange was always wider than that for Yellow.

Figure 4 superimposes the curves of Figs. 2 and 3 to allow comparisons of distributions when one name is substituted for another in an otherwise identical set of categories. Curves for Orange are displaced toward the long wavelength end of the spectrum as compared with curves for Yellow. The striking finding which emerges from the substitution of Orange for Yellow is that both the range and the location of the other curves in the name set are influenced. When Orange replaces Yellow, the Green curve shows a wider wavelength range and a shift toward the long wavelength end of the spectrum; the Red curve's rise is also shifted toward the long wavelength end of the spectrum. A similar, though less pronounced shift occurs in the distributions for Blue. This wavelength displacement is statistically significant at the .005 level for Red and at the .05 level for Green, and occurs independently of luminance level.

Results from Condition $C$ appear in Fig. 5. This condition specified the same four category names as Condition B-1, i.e., Blue, Green, Yellow, and Red, together with combinations of any two of these names. Of the eight name curves obtained at each luminance level, only those for Blue and Red peak at $100 \%$. Frequency was consistently greater for Red-Blue, Blue, Green, Yellow-Red, and Red than for BlueGreen, Yellow-Green, and Yellow. As in the other conditions, a greater number of Yellow responses occurred at the high luminance level than at the low. Peaks of Green, Yellow-Green, and Red curves showed displacements toward the short wavelength end of the spectrum at the higher luminance level.

Figure 6 presents data for Condition D which prescribed the name categories Purple, Blue, Green, Yellow, Orange, and Red. Both the Yellow and Orange curves were relatively narrow and neither distribution reached $100 \%$. At both luminance levels, there were fewer Orange responses in this condition than there were Yellow-Red responses in Condition $C$. Luminance difference did not have an appreciable effect on the data in this condition.

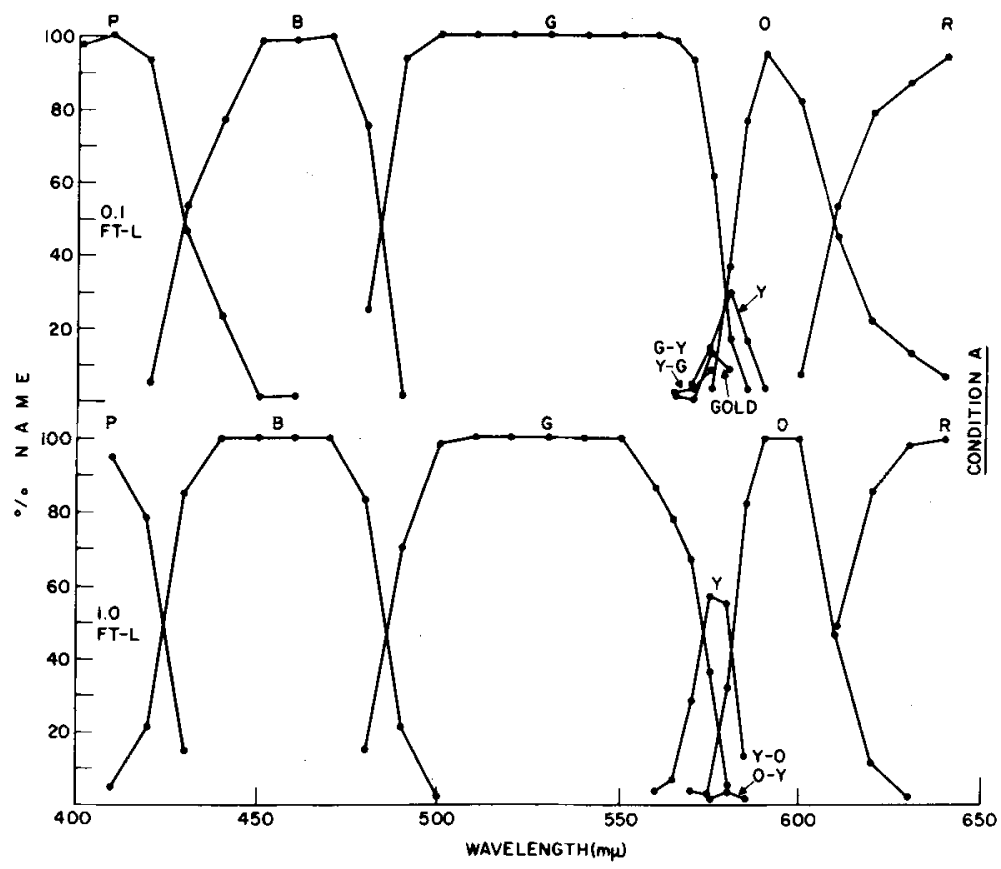

Fig. 1. Color name distributions with unrestricted choice of name (Condition A). 


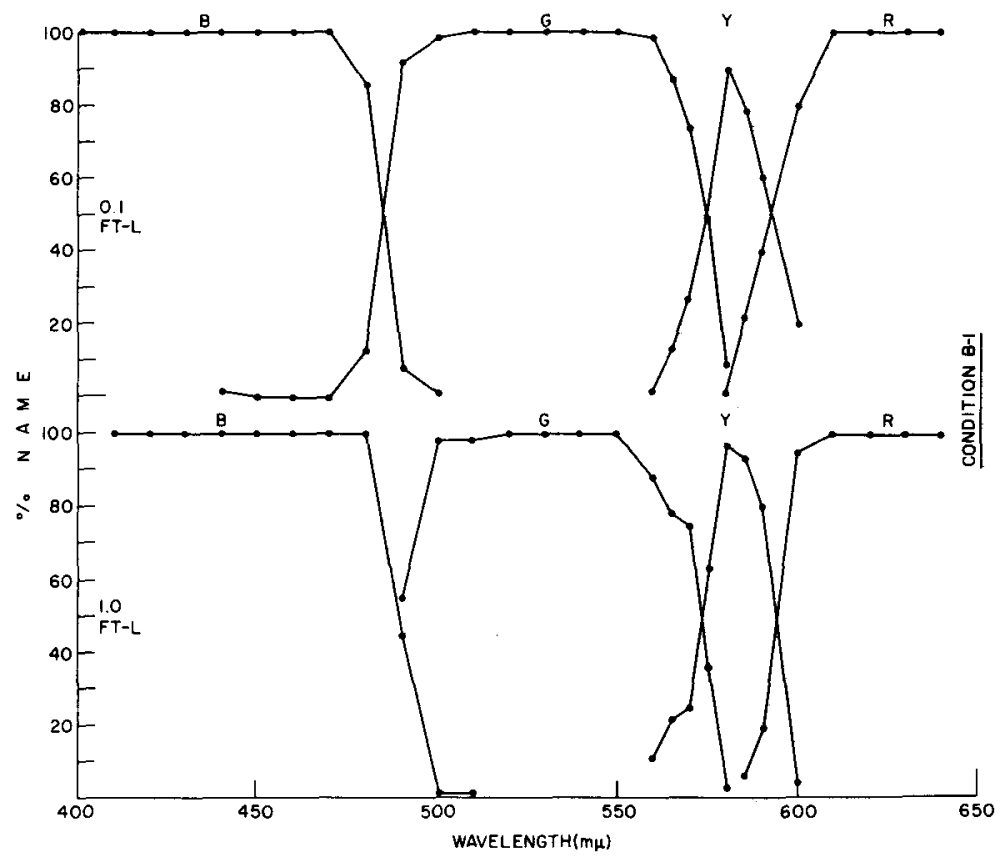

Fig. 2. Color name distributions for Blue, Green, Yellow, and Red (Condition B-1).

Figure 7 presents results from Condition E, which prescribed the six names of Condition D, i.e., Purple, Blue, Green, Yellow, Orange, and Red, as well as appropriate compounds of these names. Eleven name distributions were obtained at each luminance level, of which only the curves for Purple and Blue reached $100 \%$. The other predominating name distributions for this condition were Green, Yellow, Orange, and Red. Addition of the compound names reduced the width of the Yellow, Orange, and Red distributions in comparison to results for Condition D, and Yellow and Yellow-Green reached a higher percentage at the higher of the two luminances. Green was displaced toward the short wavelength end of the spectrum at the higher of the two luminance levels.

\section{Discussion}

Although the two luminance levels employed in these experiments were not radically different, the Bezold-Brücke shift in hue, as inferred from name
Fig. 3. Color name distributions for Blue, Green, Orange, and Red (Condition B-2).

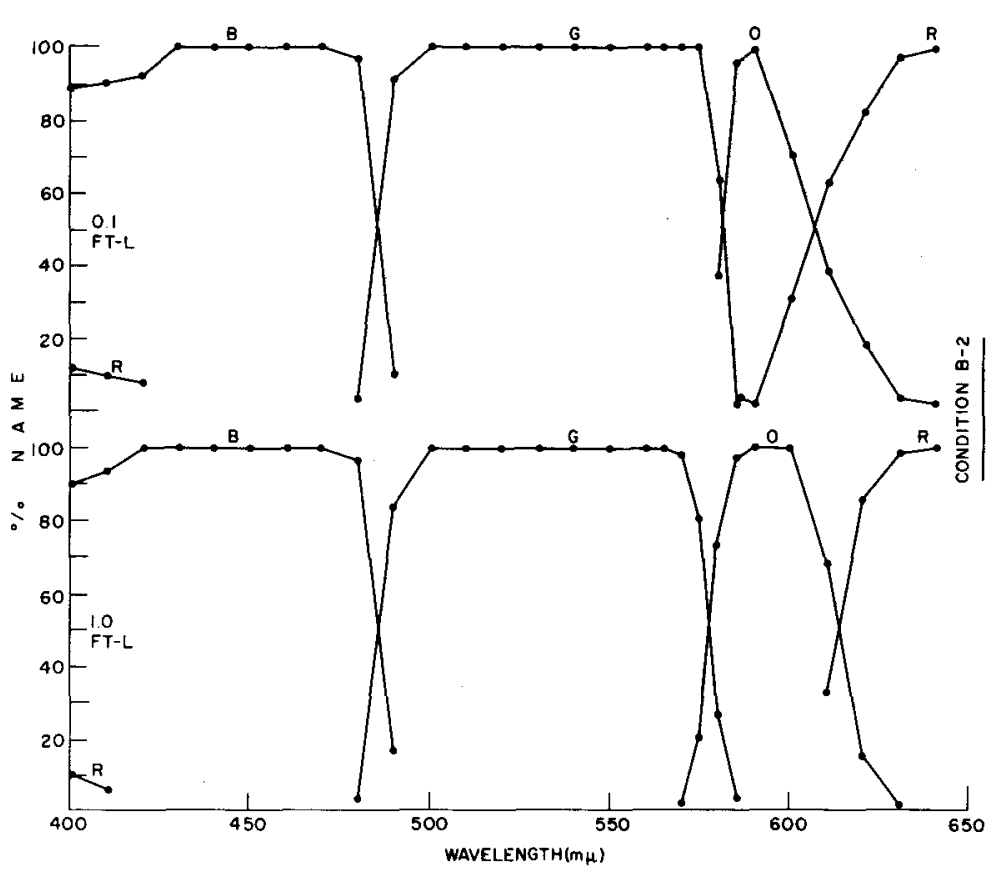




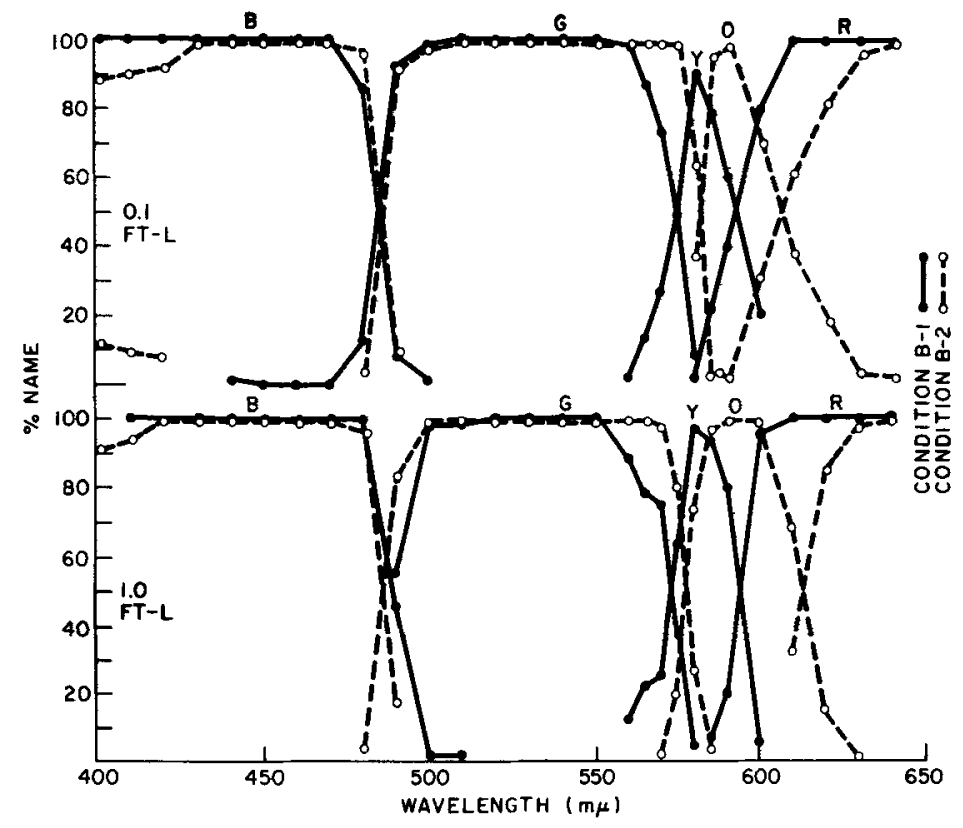

Fig. 4. Comparison of the distributions obtained from Conditions $B-1$ and B-2 (Four name categories).

applied, was observed. This shift in named hue with increased luminance was most apparent in the YellowGreen portion of the spectrum. In this area many stimuli were judged Green at low luminance, while at the higher luminance they were judged Yellow.

The basic finding that a clear-cut relationship exists between color name and wavelength has been reaffirmed by the data from this experiment. At the same time the data demonstrate that this relationship is highly sensitive to instructional manipulation.
The curves of Fig. 1, from instructions which specified no categories, bear a striking similarity to those of Fig. 6, obtained in response to instructions specifying the names Purple, Blue, Green, Yellow, Orange, and Red. In the absence of specific naming instructions, Ss will, nevertheless, assign the same color name to roughly the same wavelength region in a reliable and consistent manner, so that definite wavelength regions have come to correspond to definite color names. This correspondence may be more
Fig. 5. Color name distributions for Blue, Green, Yellow, Red, and compounds (Condition C).

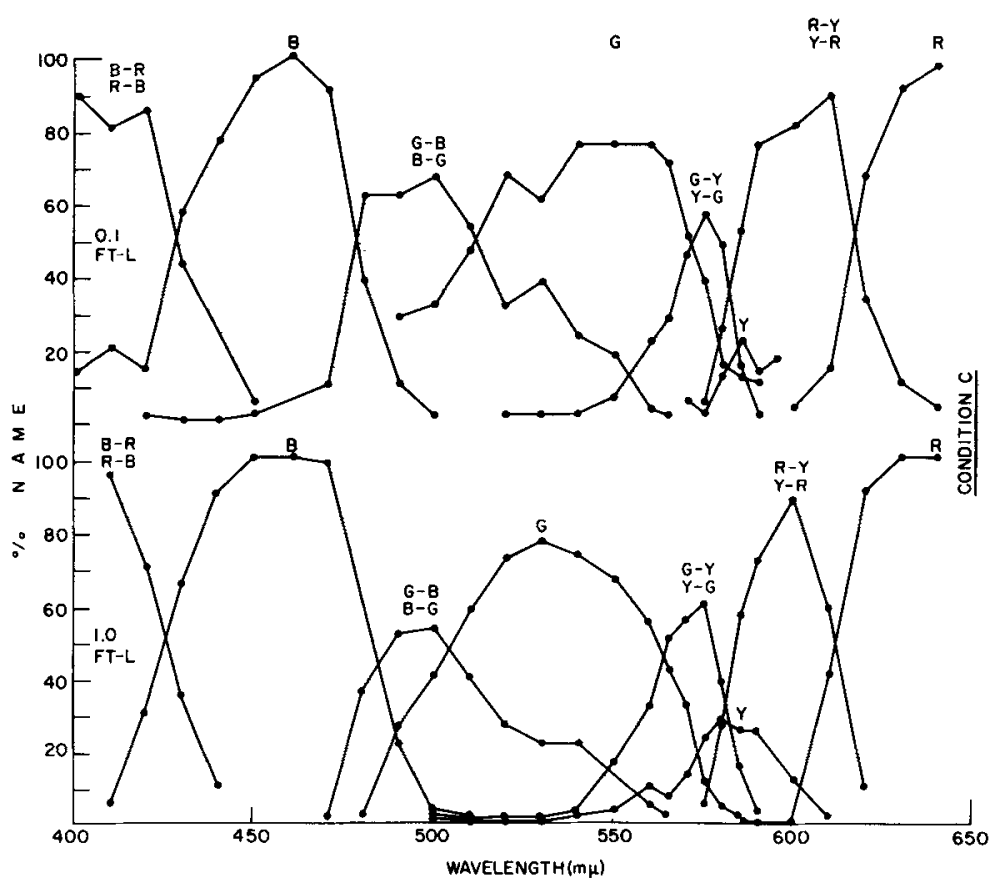




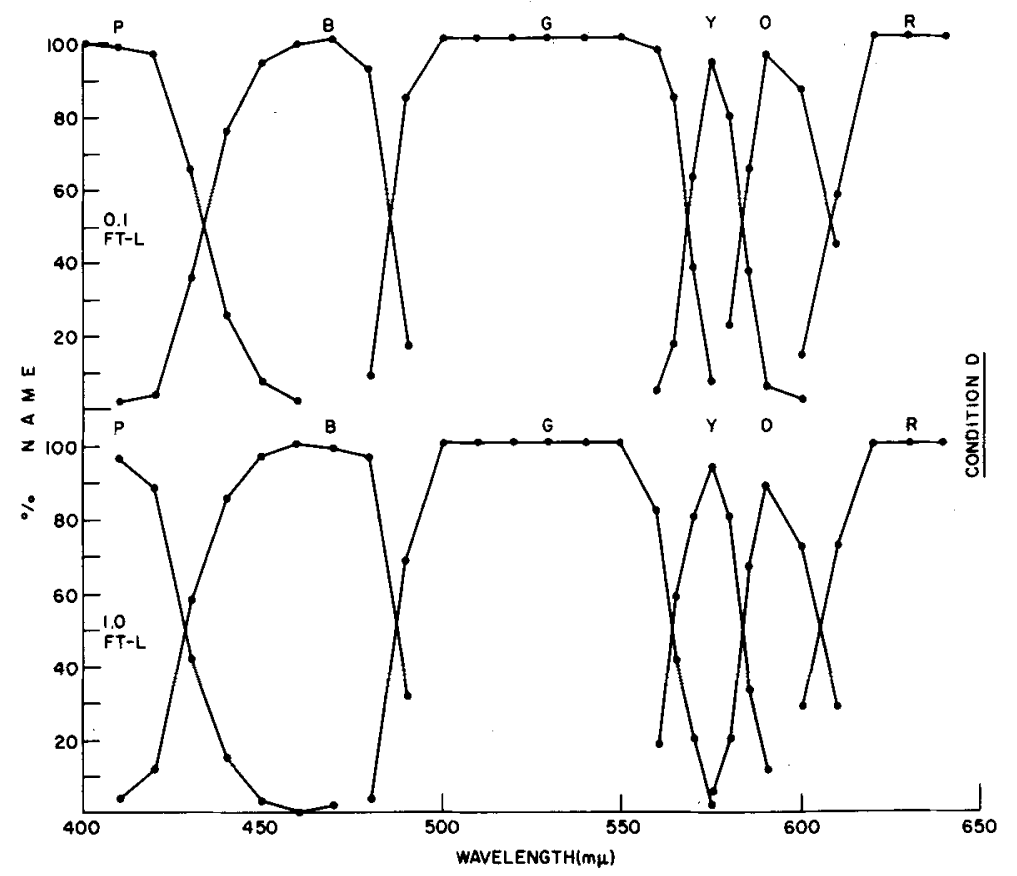

Fig. 6. Color name distributions for Purple, Blue, Green, Yellow, Orange, and Red (Condition D).

refined for Ss who are highly trained in color observations, and may vary from our observed pattern when non-English speaking Ss are employed.

When responding is limited by experimentally restricting the S's repertoire of color names, the resulting frequency distributions will be similarly limited. When, on the other hand, a large number of names are made avallable, the peak frequencies are lower and extend over a smaller wavelength range than when fewer naming categories are avail- able. An overall view of the data shows that the greater the prescribed response availability, the greater also the response dispersion. The basic wavelength-name relationship, however, acts as the limiting factor to this response dispersion.

The remarkable influence which a change in the nature of the name exerts on the data was a major finding. Results plotted in Fig. 4 indicate that when only one response category differs, Ss will respond differently not only to the changed category, but also
Fig. 7. Color name distributions for Purple, Blue, Green, Yellow, Orange, Red and compounds (Condition E).

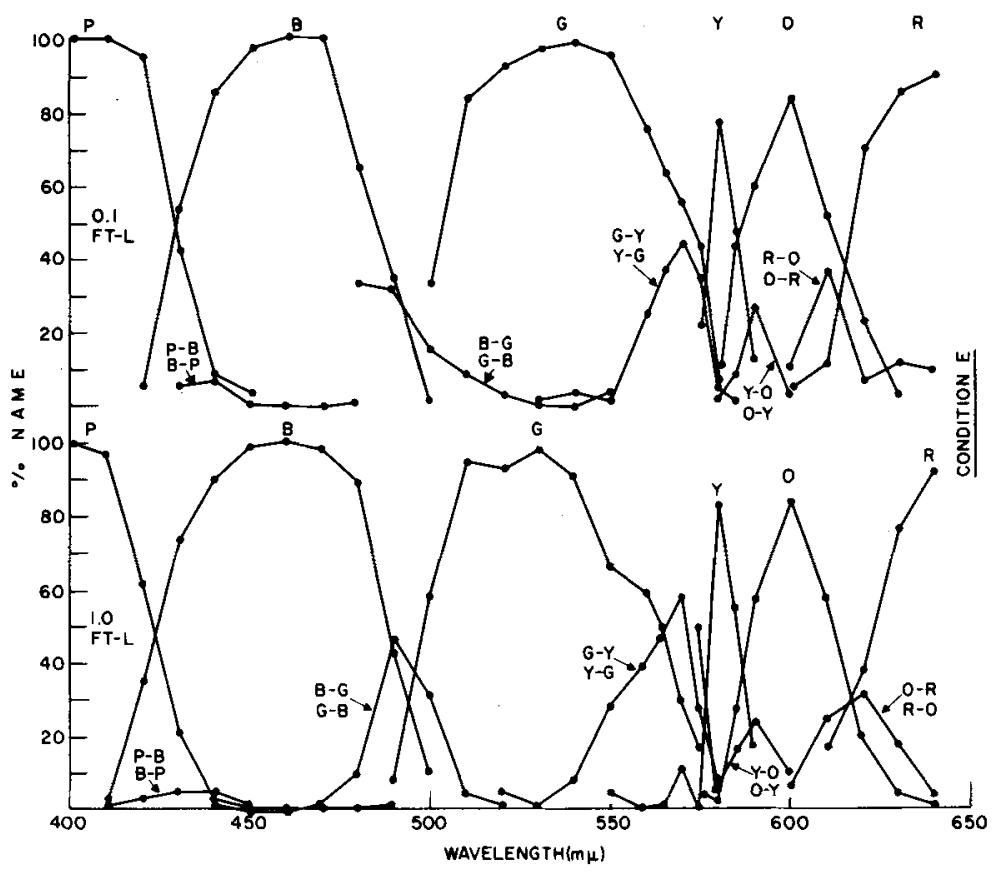



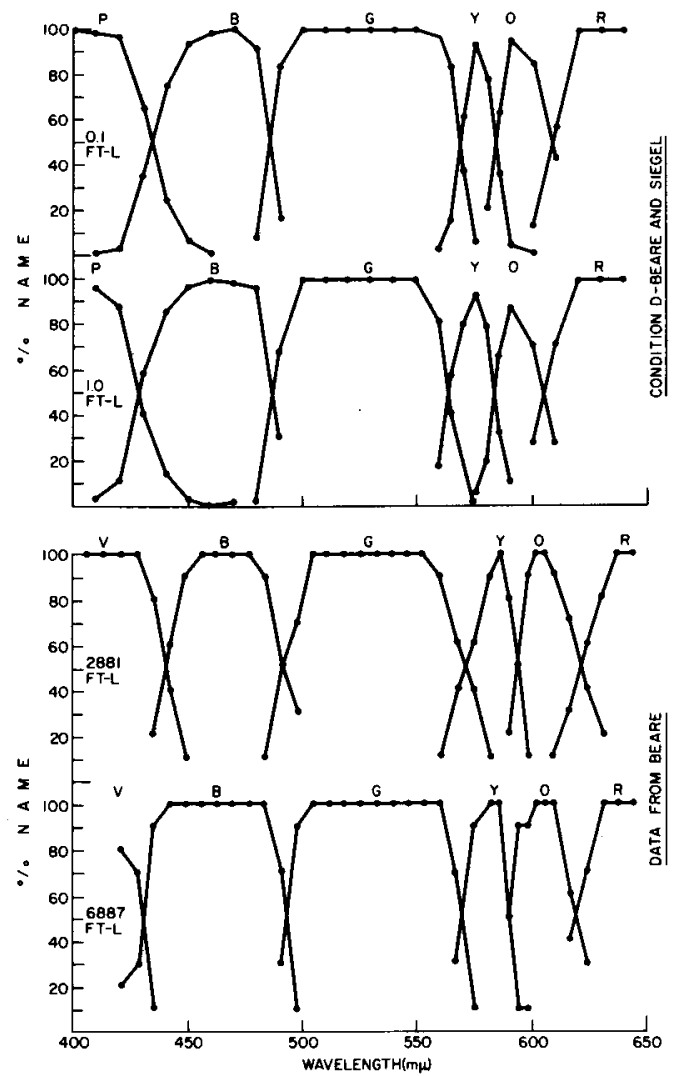

Fig. 8. Color name distributions for six name categories under two different experimental conditions and four luminance levels.

to the ones which remain common to the two conditions. A S's response pattern, then, is determined by the combined influence of all the available categories.

How the combination of both number and nature of name categories significantly affects response patterns can be studied in two ways: (1) by examining the curve for one name which occurs in two or more differing conditions, and (2) by examing the curves for two different names which are commonly used to describe the same hue. As an example for the first instance, the median wavelength for Red is significantly longer for Conditions $E, D$, and $C$ than for Conditions C, A, and D, respectively (see Table 3). As an example for the second instance, the names Yellow-Red and Orange, which are generally thought of as equivalent, are shown to have significantly different median wavelengths in Conditions $C$ and $D$, respectively. In Condition $\mathrm{C}$ both Yellow-Red and Red were available as categories, while in Condition D Orange and Red were permitted.

Within each of the six experimental conditions used in this study, Ss responded highly consistently. This consistency has been observed by others employing color naming as the experimental technique (Boynton \& Gordon, 1965, p. 86), but is retained only as long as the instruction components for the Ss are not changed. For this reason, a discussion of the uniqueness of a particular name (Sternheim \& Boynton, 1966) has no meaning except in the context of the total available name categories. Figure 8 provides the final illustration of this point by showing data from Condition $D$, together with data obtained by Beare (1963). Exposure time, brightness levels, Ss, and wavelength exposure steps were different for the two experiments. The common features of the two experiments were the naming methodology, the fact that all luminance levels were photopic, and the similarity in number and nature of prescribed name categories. The similarity between the two sets of data confirms the conclusion that, within specified luminance levels, the same instruction set will reliably produce comparable naming distributions.

Changes in response availability, although apparently minor, produce important changes in the S's response pattern. Although the choice of specific color categories must remain dependent upon the $E$ 's theoretical biases, it must be understood that this choice will have a profound influence upon the data.

\section{References}

Beare, A. C. Color-name as a function of wavelength. Amer. $J$. Psychol., 1963, 76, 248-256.

Boynton, R. M., \& Gordon, J. Bezold-Brücke shift measured by color-naming technique. J. Opt. Soc. Amer., $1965,55,78-86$.

Boynton, R. M., Schafer, W., \& Neun, M. E. Hue-wavelength relation measured by color-naming method for three retinal locations. Science, 1964, 145, 666-668.

Luria, S. M. Color-name as a function of stimulus-intensity and duration. Amer. J. Psychol, 1967, 80, 14-27.

Siegel, S. Nonparametric statistics for the behavioral sciences. New York: McGraw-Hill, 1956.

Stemheim, C. E., \& Boynton, R. M. Uniqueness of perceived hues investigated with a continuous judgemental technique. $J$. exp. Psychol., 1966, 72, 770-776.

\section{Note}

1. An earlier version of this paper was presented at the October 1966 meeting of the Optical Society of America. This research was conducted at Medical Research Laboratories, Research Laboratories, Edgewood Arsenal, Edgewood Arsenal, Maryland 21010.

(Accepted for publication July 12, 1967.) 